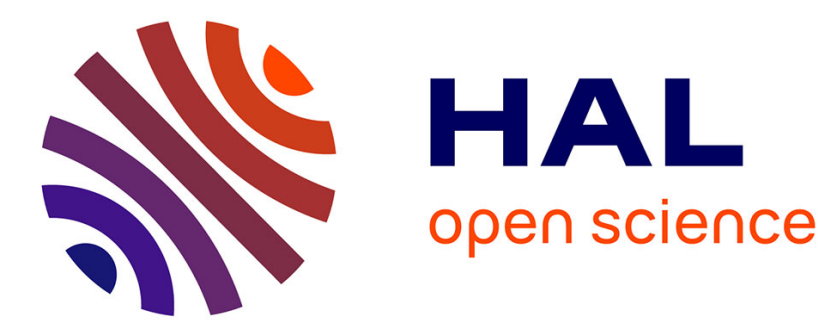

\title{
Optical characterizations of "P-down" bonded InP pump lasers
}

\author{
Solène Gérard, Christophe Starck, Francois Laruelle, Mauro Bettiati, \\ Jean-Pierre Landesman
}

\section{- To cite this version:}

Solène Gérard, Christophe Starck, Francois Laruelle, Mauro Bettiati, Jean-Pierre Landesman. Optical characterizations of "P-down" bonded InP pump lasers. Microelectronics Reliability, 2021, 126, pp.114327. 10.1016/j.microrel.2021.114327 . hal-03380254

\section{HAL Id: hal-03380254 https://hal.science/hal-03380254}

Submitted on 15 Oct 2021

HAL is a multi-disciplinary open access archive for the deposit and dissemination of scientific research documents, whether they are published or not. The documents may come from teaching and research institutions in France or abroad, or from public or private research centers.
L'archive ouverte pluridisciplinaire HAL, est destinée au dépôt et à la diffusion de documents scientifiques de niveau recherche, publiés ou non, émanant des établissements d'enseignement et de recherche français ou étrangers, des laboratoires publics ou privés. 


\title{
Optical characterizations of "P-down" bonded InP pump lasers
}

\author{
S. Gérard ${ }^{\mathrm{a}, \mathrm{b}^{*}}$, C. Starck ${ }^{\mathrm{a}}$, F. Laruelle ${ }^{\mathrm{a}}$, M.Bettiati ${ }^{\mathrm{a}}$ J.P. Landesman $^{\mathrm{b}}$ \\ a 3SP Technologies S.A.S, Route de Villejust, F-91625 Nozay, France \\ ${ }^{\mathrm{b}}$ Univ Rennes, INSA Rennes, CNRS, Institut Foton-UMR 6082, F-35000 Rennes, France
}

\begin{abstract}
We investigate the effects of the assembly process and its parameters on the optical polarization in InP pump lasers for telecommunications. Different measurements were performed for this study, such as degree of polarization of the laser emission below and above the threshold current, as well as the evaluation of the induced strain in the materials by measuring the degree of linear polarization of the photo-luminescence. We demonstrate that the soldering process parameters can affect the emission polarization both below and above the laser threshold current.
\end{abstract}

\section{Introduction}

Raman amplification in telecommunication fibers requires very high power pump lasers and a very high polarization rate [1]. In this context, the wafer manufacturing as well as the soldering and bonding conditions of these pumps must minimize power losses and optical failures. The "p-down" bonding technique allows to reduce the thermal stress linked to the heat dissipation in the component [2]. However, this bonding technology brings the active region of the chip very close to the solder pad interface, which makes the device very sensitive to the assembly process quality. The mechanical stresses resulting from the bonding can have an impact on the proper functioning of the laser, its lifetime and its electro-optical performances, such as polarization.

It has been established that in semiconductor lasers, the polarization of the emission below the threshold current is influenced by the built-in stress in the quantum wells within the active region [3]. This intrinsic stress as well as any external stress caused by the bonding process impacts the polarization state of the spontaneous emission at low driving current. The polarization state of the laser emission above the threshold current is related to the properties of the guided optical mode, in the case of single transverse and lateral mode lasers.

In this paper, we investigate which step of the bonding assembly process, burn-in and annealing and which parameters in this process influence the polarization below and above the threshold current.
Table 1

Summary of soldering conditions

\begin{tabular}{lll}
\hline $\begin{array}{l}\text { Sample } \\
\mathbf{n}^{\circ}\end{array}$ & $\begin{array}{l}\text { Collets for } \\
\text { bonding : } \\
\text { Rigid or flexible }\end{array}$ & $\begin{array}{l}\text { Annealing condition : } \\
\text { Below or above eutectic } \\
\text { temperature }\end{array}$ \\
\hline $1-2$ & Flexible & Above eutectic $\left(340-370^{\circ} \mathrm{C}\right)$ \\
$3-5$ & Flexible & Below eutectic $\left(240-270^{\circ} \mathrm{C}\right)$ \\
$6-8$ & Rigid & Above eutectic $\left(340-370^{\circ} \mathrm{C}\right)$ \\
$9-10$ & Rigid & Below eutectic $\left(240-270^{\circ} \mathrm{C}\right)$ \\
\hline
\end{tabular}

The influence of some parameters of the process has been studied in order to optimize the laser emission polarization.

\subsection{Experimental methodology}

The components analyzed in this study are high power semiconductor laser diodes emitting in the 1400-1500 $\mathrm{nm}$ band in InP technology [4]. A schematic cross section of the $(\mathrm{p} / \mathrm{n})$ buried heterostrucure $(\mathrm{p} / \mathrm{nBH})$ of the laser diode is shown in fig.1. These chips are bonded "p-down" to an AlN submount with AuSn solder alloy whose eutectic temperature is $280^{\circ} \mathrm{C}$. We used two different collets for the bonding, a "rigid collet" which places the chip on the solder pad parallel to its surface and a "flexible collet" which allows a more homogeneous wetting of the chip along its length on the solder pad. After soldering, we first subjected these samples to three steps of burn-in at high temperature, strong 


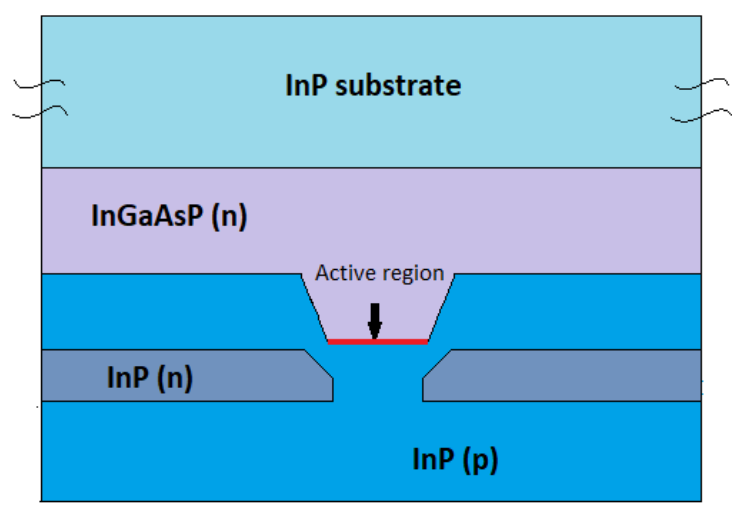

Fig. 1. Cross section diagram of the pnBH structure of the laser diode.

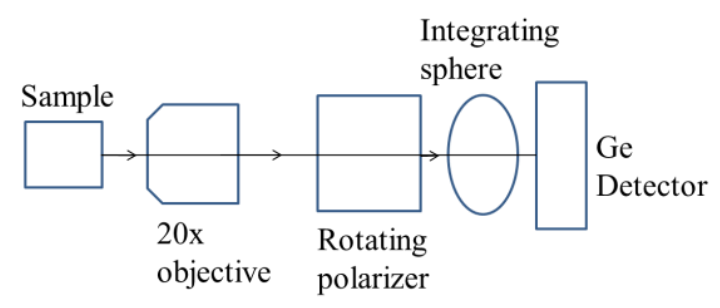

Fig. 2. Schematic diagram of the laser emission extinction ratio measuring equipment.

driving current. Under these conditions, no lasing emission occurs from the devices. All samples underwent the same burn-in conditions. These chipson-submount $(\mathrm{CoS})$ devices were then annealed, either above the eutectic temperature in the range of $340^{\circ} \mathrm{C}-370{ }^{\circ} \mathrm{C}$ or below the eutectic temperature in the range of $240{ }^{\circ} \mathrm{C}-270{ }^{\circ} \mathrm{C}$. A summary of the soldering and annealing conditions is presented in Table 1.

All the samples were characterized by two types of measurements in addition to the standard electrooptical characterization. First, the set-up for measurement of the polarization of the laser emission is presented in Fig.2. The laser beam is collimated through a non-polarizing microscope objective and passes through a rotating Glan-Taylor calcite polarizer with an extinction ratio of 100000:1. The transmitted power along the two polarization axes (transverse electric (TE), with the electric field parallel to the plane of the quantum well layers and transverse magnetic (TM), with the electric field perpendicular to the plane of quantum well layers) is measured for currents ranging from 0 to $1500 \mathrm{~mA}$. The power versus current characteristics of all samples are shown in fig.3. The threshold current of these components is in the range $95-100 \mathrm{~mA}$ and

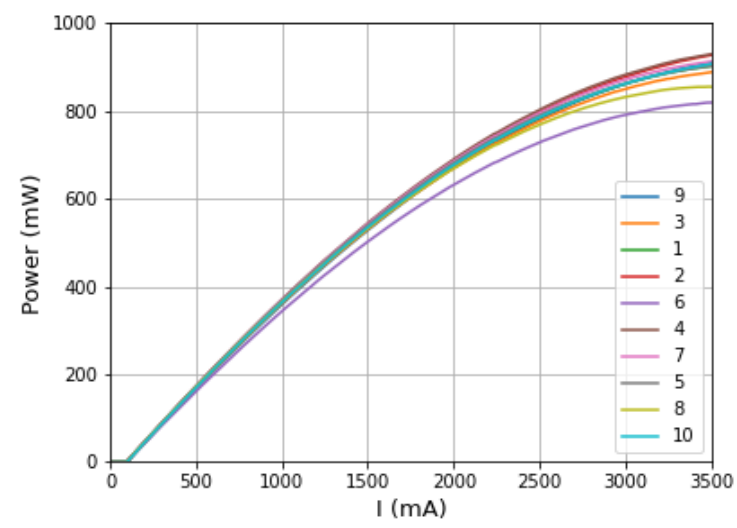

Fig. 3. Light current measurements at $25^{\circ} \mathrm{C}$ after bonding of samples presented in Table 1.

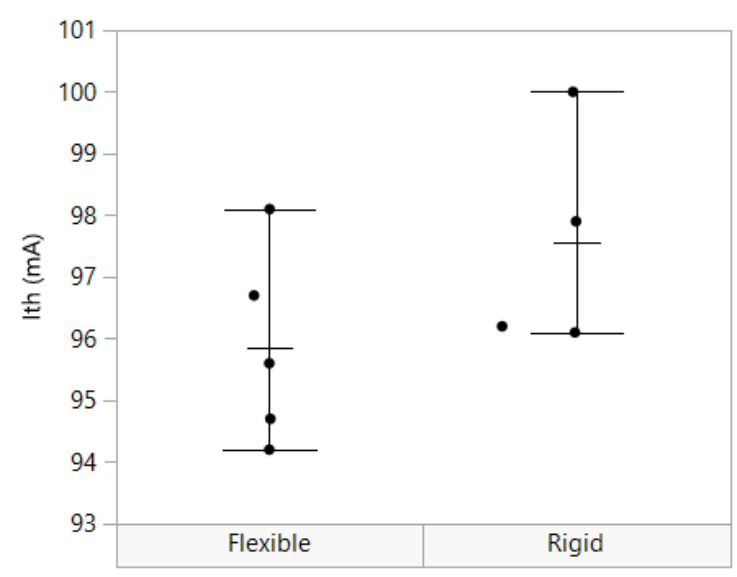

Fig. 4. Threshold current at $250^{\circ} \mathrm{C}$ after bonding of all samples depending of the collet used for bonding.

scattering is typical of a homogeneous batch.

We choose to express the polarization rate of the laser emission below the current threshold by the degree of polarization (DOP) (see Eq.1), taking the form of a number between -1 and 1 , and above the threshold current by the polarization extinction ratio (PER) (see Eq.2), expressed in dB.

$$
\begin{aligned}
& D O P=\left(P_{T E}-P_{T M}\right) /\left(P_{T E}+P_{T M}\right) \\
& P E R=10 * \log \left(P_{T E} / P_{T M}\right)
\end{aligned}
$$

with $P_{T E}$ and $P_{T M}$, the powers measured along the two polarization axes TE and TM.

We then associated these measurements with an analysis of the strain in the materials by a mapping of the degree of linear polarization of the photoluminescence (DOLP-PL) of the laser diode front facet. This allows to determine the anisotropic stress existing in the semiconductor depending of the bonding conditions [5]. 


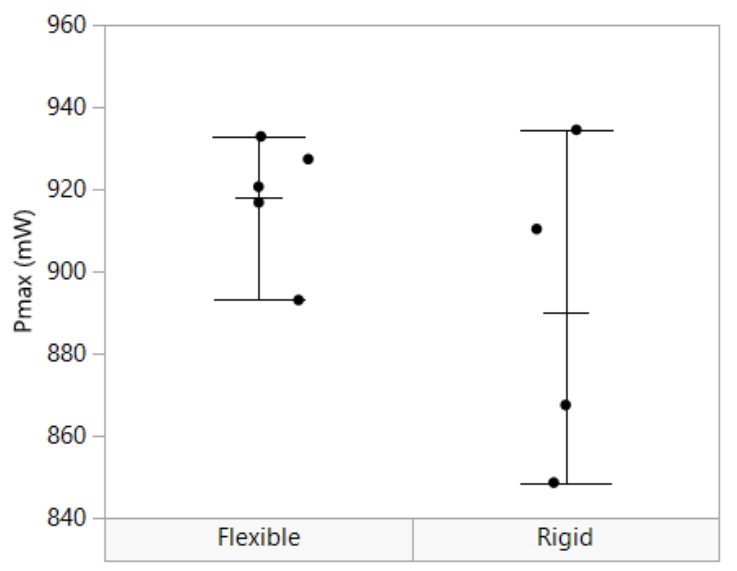

Fig. 5. Maximal power at $25^{\circ} \mathrm{C}$ after bonding of all samples depending of the collet used.

\section{Results}

\subsection{Effect of the collet used for bonding}

\subsubsection{Impact of collet on electro-optical performances}

In the first place, it is important to analyse the impact of different soldering conditions on the operation of the laser under the desired conditions of use as well as during burn-in. This selection step can be considered as a way to predict the component reliability.

Fig.4 and Fig.5, respectively show the current threshold and the maximal power of the samples described in Table 1 just after the bonding and depending to the collet used during the assembly step. Vertical lines represent the maximum values and the average of the batches. We don't see any effect of the collet on these parameters.

\subsubsection{Impact of the collet on polarization}

The degree of polarization below the threshold current was measured on laser diodes bonded with the two different collets as described in Table 1. The results of the DOP measurements after soldering are presented in Fig.6. We show here the variation of the DOP as a function of the current from $0 \mathrm{~mA}$ to the threshold current. The dotted blue curves are the measurements of $\mathrm{CoS}$ bonded with the rigid collet and the continuous red curves are the measurements of $\mathrm{CoS}$ bonded with the flexible collet.

These results show an average difference in DOP between the two soldering conditions of 0.07 . The collets used do not generate the same stresses in the chips and have a different impact on the spontaneous emission rate of TE and TM photons

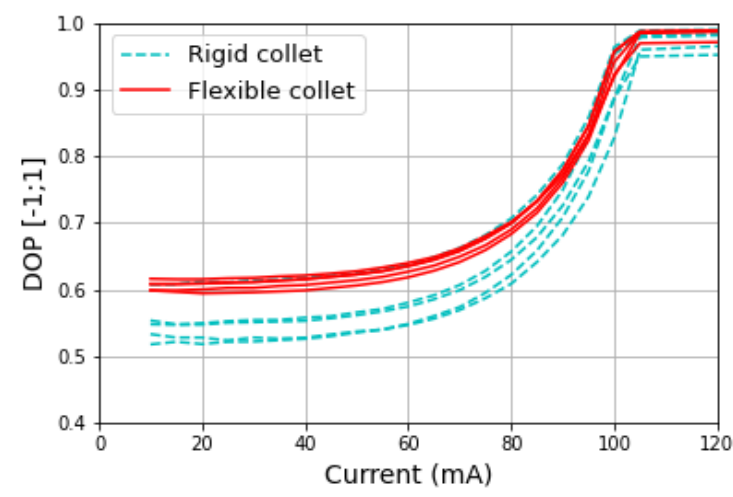

Fig. 6. DOP of the laser emission below the threshold current. Continuous red lines: samples 1 to 5 bonded with flexible collet. Dotted blue lines: samples 6 to 10 bonded with a rigid collet.

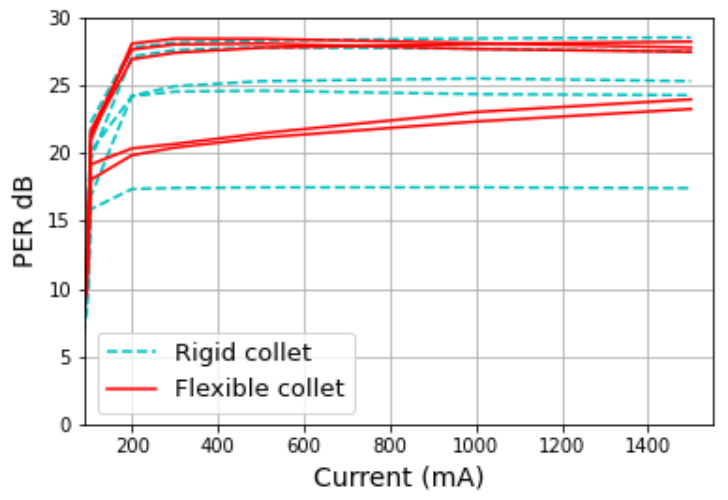

Fig. 7. PER of the laser emission below the threshold current. Continuous red lines: samples 1 to 5 bonded with flexible collet. Dotted blue lines: samples 6 to 10 bonded with a rigid collet.

[3],[6].

However, the PER values above the threshold current, do not depend on the collet used and are widely scattered, as can see in Fig.7.

\subsection{Effect of burn-in and annealing}

2.2.1. Impact of burn-in and annealing on electrooptical performances

First, the impact of burn-in and annealing on basic electro-optic parameters were analysed depending on the collet used for the bonding and the type of annealing they underwent.

We defined the drift parameter as the difference between two steps. The drift in the threshold current and the power at 3.5A after burn-in are included in the uncertainty of measurement, regardless of the collet used for bonding upstream. 


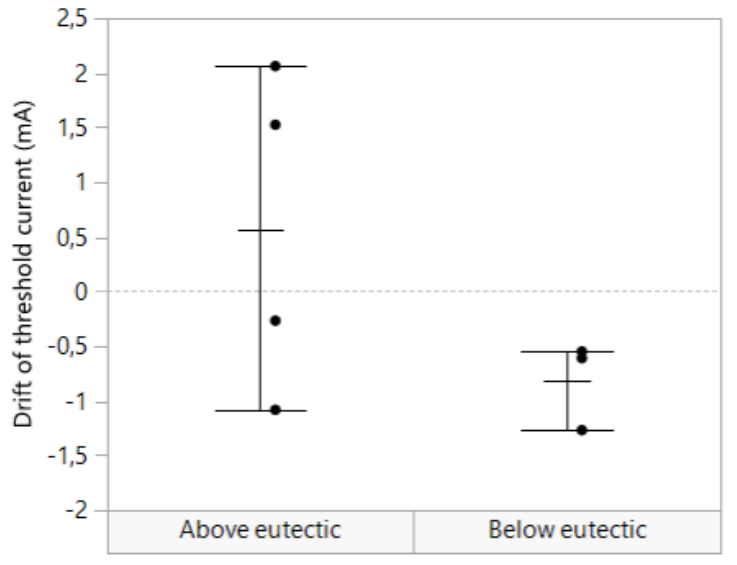

Fig. 8. Drift of threshold current after annealing above or below the eutectic temperature.

Regarding the effect of annealing, the drift of threshold current after both types of annealing doesn't exceed the authorized drift specification. Fig.8 shows the drift of threshold current after annealing below or above the eutectic temperature. The drift is not very important, but nevertheless seems to be more scattered in the case of an annealing above the eutectic temperature. As for the collet used, it has no impact on this parameter.

On the other hand, the analysis of the power drift at $3.5 \mathrm{~A}$ after annealing above eutectic temperature seems to show a greater dispersion than after annealing below eutectic temperature, but it is not yet possible to conclude on the cause of this scattering.

\subsubsection{Effect on polarization}

Polarization measurements (DOP, PER) were carried out after each step of the burn-in process and after annealing. The results show that the burn-in steps do not have an influence on the DOP and PER of the different CoS. Continuous lines in Fig.9 and Fig.10 show the PER measurements for two different samples at each step of burn-in.

However, annealing appears to have a strong impact on the PER, when it is carried out above the eutectic temperature of the solder. A decrease of the maximum PER value of $4 \mathrm{~dB}$ (i.e. a difference in power ratio before and after annealing of more than $50 \%$ ) was measured on the five samples which were annealed at this temperature while the five samples annealed below the eutectic temperature did not appear to be impacted. The dotted line in Fig.9 shows an example of the decrease of the PER above the threshold current for one $\mathrm{CoS}$ bonded with a flexible collet and annealed above the eutectic

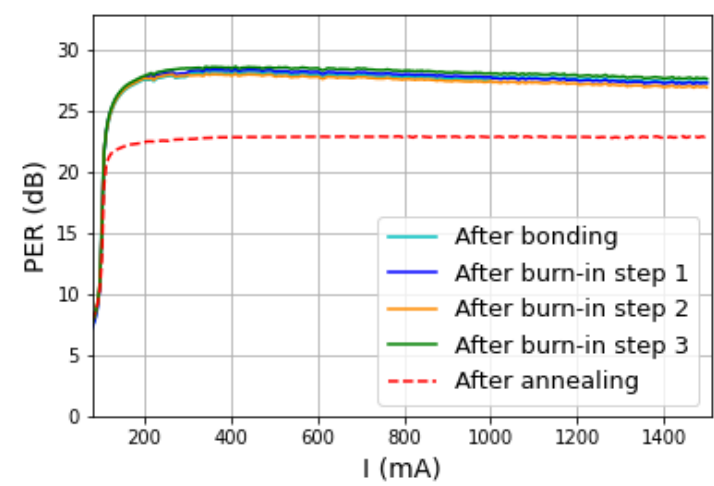

Fig. 9. PER of sample 2 after each step of the burn-in process and annealing above the eutectic temperature.

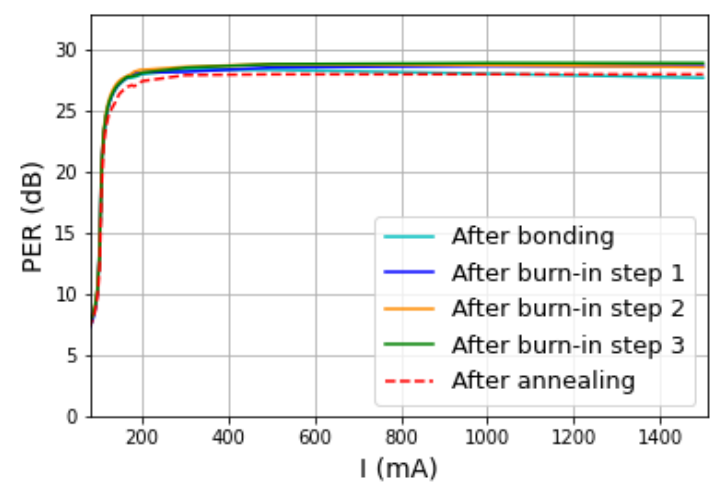

Fig. 10. PER of sample 3 after each step of the burn-in process and annealing below the eutectic temperature.

temperature (sample 2 in Table 1) in comparison with one $\mathrm{CoS}$ also bonded with a flexible collet but annealed below the eutectic temperature (sample 3 in Table 1) in Fig. 10.

DOLP-PL mapping is sensitive to non-biaxial strain, so one can measure only anisotropic strain inside the structure [5]. Indeed, a stress-free crystal emits photoluminescence (PL) in a random direction of polarization. When it is strained in an anisotropic way, the PL will be partly linearly polarized. The DOLP is the degree of linear polarization defined in [7] and is proportional to the anisotropic strain (see Eq.3). It is expressed between 0 and 1 .

$$
D O L P=\mid \text { C. }\left(\varepsilon_{\mathrm{xx}}-\varepsilon_{\mathrm{zz}}\right) \mid
$$

With $\varepsilon_{\mathrm{xx}}$ and $\varepsilon_{\mathrm{zz}}$ the strains in the two principal axes of deformation.

The direction of polarization is rotated 90 degrees with respect to the direction of maximum principal deformation.

In order to be able to characterize the mechanical stress present in the chips before and after annealing, DOLP measurements were carried 
a)

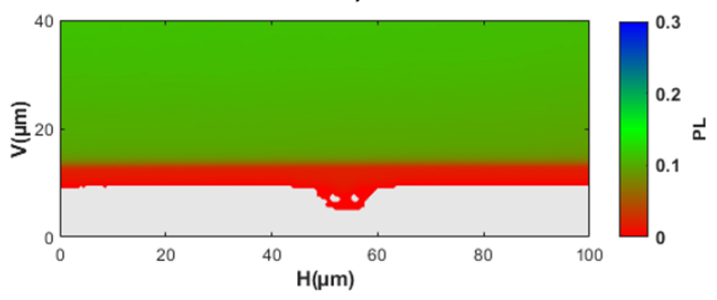

b)

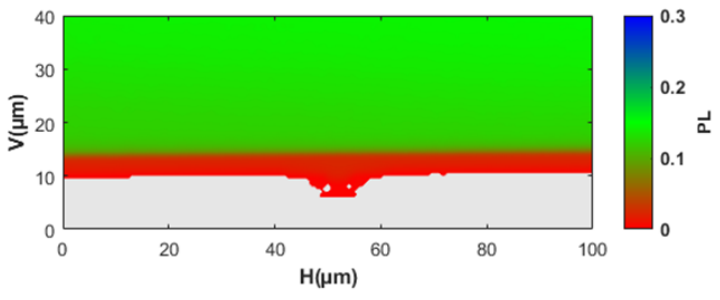

Fig. 11. Photoluminescence intensity of a $\mathrm{CoS}$ before (a) and after annealing above eutectic temperature (b).

a)

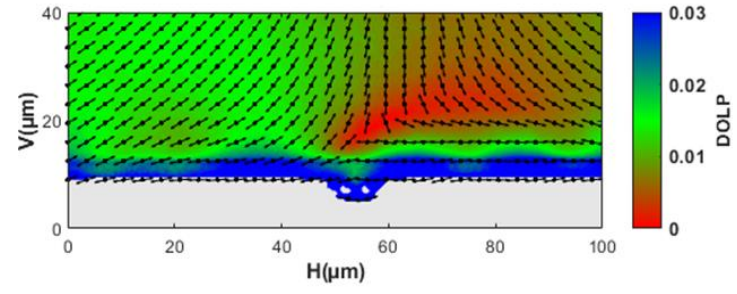

b)

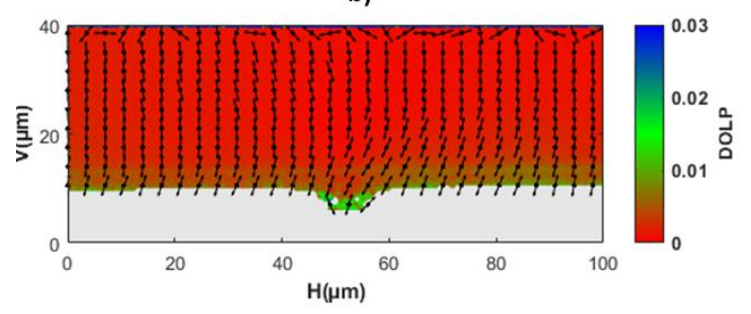

Fig. 12. DOLP of a CoS before annealing (a) and after annealing above eutectic temperature (b).

out on several CoS. A mapping of the front facets of these samples, gives us information on the strain present at the facet, near the emission area. Scans of $100 \mu \mathrm{m}$ in width and $40 \mu \mathrm{m}$ in height were made in the area of the active region.

Fig.11 shows the photoluminescence intensity of a CoS that was bonded with a rigid collet before and after annealing above eutectic temperature. The photoluminescence signal is homogeneous in the the InP substrate (green color) and the InGaAsP epitaxial layer (red color). The difference in intensity of these two regions is attributed to the material type and doping level, but does not vary with annealing [8].
However, the impact of annealing is clearly seen on the variation of DOLP and polarization direction. Fig. 12 shows both the mapping of the DOLP and the direction of polarization of the photoluminescence of this same sample represented respectively by the colors and the arrows. Image a) shows the mapping of the sample before annealing and image b) after annealing above the eutectic temperature. The annealing reduces the DOLP from $1.5 \%$ to less than $0.5 \%$ in the substrate and from $3 \%$ to $1 \%$ in the epitaxial layer and reduces the dispersion in the direction of polarization. Further measurements on samples annealed above the eutectic temperature were performed and we analysed the same trend. We can conclude that the annealing process is efficient to relax the mechanical stress present in the laser diode.

\section{Discussion}

The test plan carried out on the different steps and conditions of bonding allowed us to highlight two effects impacting the degree of polarization at the two operating modes of the laser. First, below the threshold current, when the laser is in the spontaneous emission mode, the flexible collet used during the bonding seems more advantageous by increasing the polarization degree by almost 0.1 compared to the rigid collet. The stress applied near the active region of the laser favors the creation of TE photons and is therefore in agreement with the specification of a transverse electric emission polarization.

However, this trend does not seem to apply in the case of emission above the threshold current, when the laser is in a stimulated emission mode. Today, we cannot conclude on the correlation between the collet used and the PER above the threshold current but additional measurements on further samples are therefore considered for the future.

On the other hand, when the component has undergone part of the packaging process, annealing above the eutectic temperature, the stress within the laser diode decreases significantly. This effect is interesting in the context of the reliability of the component, however, the annealing also causes degradation of the PER above the threshold current, which is neither desired nor acceptable.

These preliminary results give us good information on the possible causes of a failure of the optical polarization but do not yet allow us to rule on the impact of the bonding process.

\section{Conclusion}

We have studied the impact of some steps and 
conditions of the assembly of "p-down" bonded high power laser diodes on their polarization degree. First, we showed that the standard electro-optical parameters were not impacted by the bonding conditions and the burn-in steps.

We have shown that there is no direct link between the degree of polarization as measured, below and above the threshold current. The collet used for the bonding of the chips onto the submount has an effect on the threshold current and the spontaneous emission rate of TE and TM photons, impacting the DOP below the threshold current. Burn-in steps, as a whole, do not affect the polarization. When the CoS is submitted to an annealing above eutectic temperature, the PER of the emission above threshold is strongly reduced and the front facet DOLP-PL much reduced and more homogeneous.

\section{Acknowledgements}

The authors thanks J. Chauveau for technical support. Financial support from Agence Nationale pour la Recherche Technologique Cifre grant $\mathrm{n}^{\circ}$ $2019 / 1003$ is greatly acknowledged.

\section{References}

[1] C. Headley et G. P. Agrawal, Raman amplification in fiber optical communication systems. Amsterdam; Elsevier Academic Press, 2005.

[2] X. Liu et al., "Comparison Between Epi-Down and Epi-Up Bonded High-Power Single-Mode 980-nm Semiconductor Lasers », Advanced Packaging, IEEE Transactions on, vol. 27, p. 640-646, déc. 2004, doi: 10.1109/TADVP.2004.831862.

[3] P. D. Colbourne et D. T. Cassidy, « Bonding stress measurements from the degree of polarization of facet emission of $\mathrm{AlGaAs}$ superluminescent diodes », IEEE Journal of Quantum Electronics, vol. 27, $\mathrm{n}^{\circ} 4$, p. 914-920, avr. 1991, doi: 10.1109/3.83326.

[4] J.-R. Burie et al., « Extremely low losses 14xx single mode laser diode leading to $550-\mathrm{mW}$ output power module with $0-75^{\circ} \mathrm{C}$ case temperature and $10-\mathrm{W}$ consumption », in High-Power Diode Laser Technology and Applications X, févr. 2012, vol. 8241, p. 82410X, doi: 10.1117/12.906405.

[5] D. T. Cassidy, S. K. K. Lam, B. Lakshmi, et D. M Bruce, "Strain mapping by measurement of the degree of polarization of photoluminescence », Appl. Opt., $A O$, vol. 43, n ${ }^{\circ}$ 9, p. 1811-1818, mars 2004, doi: 10.1364/AO.43.001811

[6] E. Bogdanov, H. Kissel, K. Kolokolov, et N. Minina, « TM/TE polarization tuning and switching in tensile strained $\mathrm{p}$-AlGaAs/GaAsP/n-AlGaAs heterostructures by uniaxial compression ", Semiconductor Science and Technology, vol. 31, p. 035008, févr. 2016, doi: 10.1088/02681242/31/3/035008.

[7] M. Born et E. Wolf, Principles of Optics:
Electromagnetic Theory of Propagation, Interference and Diffraction of Light. CUP Archive, 2000.

[8] J. W. Tomm et J. Jiménez, Quantum-Well Laser Array Packaging: Nanoscale Pckaging Techniques. McGraw-Hill Education, 2007. 